\title{
Design and Evaluation of Levodopa Methyl Ester Intranasal Delivery Systems
}

\author{
In Koo Chun ${ }^{\mathrm{b}}$, Yeon Hong Lee ${ }^{\mathrm{a}}$, Kyung Eun Lee ${ }^{\mathrm{a}}$ and Hye Sun Gwak ${ }^{\mathrm{a}}$, \\ ${ }^{a}$ College of Pharmacy \& Division of Life and Pharmaceutical Sciences, Ewha Womans University, Korea \\ ${ }^{\mathrm{b}}$ College of Pharmacy, Dongduk Women's University, Seoul 501-759, Korea
}

\begin{abstract}
Objectives: This study aimed to examine the feasibility of nasal powder formulations for the delivery of levodopa (L-dopa) into the brain using highly water-soluble levodopa methyl ester hydrochloride (LDME).

Methods: For designing nasal LDME powders, $\mathrm{pH}$-rate stabilities of LDME in buffer solutions and their enzymatic degradations in rabbit nasal mucosal and serosal extracts were investigated. In vitro permeation studies were carried out with four LDME nasal powders.

Results: LDME was degraded fast in weakly acidic and neutral solutions, but relatively stable in acidic solutions. In nasal extracts, LDME (50 and $200 \mu \mathrm{g} / \mathrm{mL}$ ) was rapidly hydrolyzed, forming L-dopa, and there were no significant differences in firstorder degradation rates between mucosal and serosal extracts. From the in vitro permeation studies, LDME powder formulations resulted in faster appearance rates $\left(1.07 \pm 0.39 \mathrm{mg} / \mathrm{cm}^{2} / \mathrm{hr}\right)$ of L-dopa than solution formulations $\left(0.35 \pm 0.08 \mathrm{mg} / \mathrm{cm}^{2} / \mathrm{hr}\right)$.

Conclusions: These results suggested that LDME nasal powder formulations could be useful delivery systems of L-dopa.
\end{abstract}

Keywords: Levodopa methyl ester, levodopa, nasal delivery, stability, permeation

\section{INTRODUCTION}

Parkinson's Disease (PD) is a condition precipitated by decreased dopamine (DA) in the central nervous system - therefore, treatment is geared towards ensuring an adequate supply of DA to the striatum to rectify the imbalance. However, DA cannot be administered directly because it cannot penetrate the blood brain barrier. Levodopa (L-dopa), the metabolic precursor of DA, has been regarded as the standard for treating parkinson's disease [1]. L-dopa exerts its action by replacing the DA that would be normally released by the substantia nigra. It can cross the blood brain barrier via a saturable transporter and is converted to DA by

\footnotetext{
*Correspondence to: Hye Sun Gwak, College of Pharmacy \& Division of Life and Pharmaceutical Sciences, Ewha Womans University, Seoul 120-750, Korea. Tel.: +82 23277 4376; Fax: +82 2 3277 2851; E-mail: hsgwak@ewha.ac.kr.
}

L-aromatic amino acid decarboxylase (also known as dopa decarboxylase) in the brain [2,3].

Currently, the oral route is the most popular clinically available route for L-dopa administration in PD patients. However, oral administration of L-dopa causes variable and unreliable clinical responses. Since L-dopa is immediately absorbed in the proximal duodenum by an active transport system, its plasma concentrations rapidly fluctuate. The rates and extents of L-dopa absorption may be affected by diet and other gastric factors. Saturable large neutral amino acids such as leucine, valine, phenylalanine, tyrosine, and methionine contained in food may compete with L-dopa for intestinal absorption [4, 5]. Thus, a highprotein diet reduce the absorption of L-dopa from the intestines. Constipation and slowing the gastric emptying influence the intestinal absorption in a negative way.

In addition, dysphagia is a well-recognized manifestation of PD; the prevalence of dysphagia is uncertain 
but may be as high as $52 \%$ in this disease. Patients experiencing this manifestation cannot be expected to comply with oral administration or to obtain optimal bioavailability of L-dopa [6, 7].

A nasal delivery system has been considered as an alternative dosage form to oral delivery. The nasal cavity is easily accessible, extensively vascularized, and highly permeable. The large surface area of the nasal mucosa affords rapid absorption, fast onset of therapeutic effect, and higher bioavailability. Compounds administered via this route are absorbed directly into the systemic circulation, avoiding the hepatic first-pass effect [8-10]. In our previous study [11], nasal delivery systems were formulated using L-dopa and found to be a favorable administration route. However, due to its low solubility, it was not possible to load a sufficient amount of L-dopa.

Levodopa methylester hydrochloride (LDME) is a highly soluble prodrug produced by the esterification of L-dopa. The molecular weight of LDME is $314 \mathrm{mg}$, which is equivalent to $250 \mathrm{mg}$ of L-dopa. LDME is known to be about 250 times more soluble than L-dopa [12]. Therefore, it was expected that this compound could successfully overcome the solubility problem of L-dopa. Kao et al. (2000) reported the nasal administration of the water soluble prodrugs of L-dopa, but they mainly used pure butyl ester of L-dopa without further formulation for nasal delivery [13].

The objective of this study was to evaluate the feasibility of nasal delivery of LDME by investigating its physicochemical and enzymatic stability, formulating nasal delivery systems, and characterizing the permeation of L-dopa through rabbit nasal mucosae.

\section{MATERIALS AND METHODS}

\section{Animals}

Male New Zealand White rabbits weighing 2.5-3.5 kg were obtained from Samtako Bio Co., Ltd. (Osan, Korea).

\section{Materials}

Levodopa (L-dopa), carbidopa (C-dopa), 1-3,4dihydroxyphenylalanine methyl ester hydrochloride (levodopa methyl ester, LDME) and $\alpha$-methyldopa were purchased from Sigma Chemical Co. (St. Louis, MO, USA). Silicated microcrystalline cellulose (SMCC, Mendell, Patterson, NY, USA), 2-hydroxypropyl- $\beta$-cyclodextrin (2-HP $\beta C D$, Cargill Inc., Minneapolis, MN, USA), hydroxypropyl cel- lulose (HPC, Aqualon, Wilmington, DE, USA), Carbopol 974 P (Noveon Inc., Cleveland, OH, USA), carboxymethyl cellulose-Na (CMC-Na, Junsei Chem. Co. Ltd., Kyoto, Japan), Xylazine (Bayer Korea, Ansan, Korea), tiletamine-xolazepam (Virbac Korea Medicine, Seoul, Korea), ether (Daejung Chemicals and Metals, Siheung, Korea), heptanesulphonate, disodium ethylenediamine tetraacetic acid (EDTANa 2 , citric acid, sodium citrate, perchloric acid, orthophosphoric acid, maleic acid, and triethanolamine (Duksan Pure Chemical, Ansan, Korea) were also obtained. Methanol was used for HPLC analysis. Other reagents were of analytical grade.

\section{Chromatographic conditions}

Samples were analyzed by high-performance liquid chromatography (HPLC). The HPLC system consisted of a pump (PU-2080, Jasco, Tokyo, Japan) with an electrochemical detector (CouloChem III, ESA, Muskegon, MI, USA). The first electrode in the analytical cell was set at $-400 \mathrm{mV}$ (Range $100 \mu \mathrm{A}$ ) and the second one at $450 \mathrm{mV}$ (Range $100 \mathrm{nA}$ ) with a flow-rate of $1 \mathrm{~mL} / \mathrm{min}$. A Gemini $5 \mu \mathrm{C} 18$ column $(4.6 \times 150 \mathrm{~mm}, 5 \mu \mathrm{m}$ bead size, Phenomenex, Torrance, CA, USA) was used. The mobile phase was composed of $16.5 \mathrm{~g}$ of potassium phosphate, $1.0 \mathrm{~mL}$ of $0.1 \mathrm{M} \mathrm{EDTANa} 2,1.2 \mathrm{~mL}$ of $0.5 \mathrm{mM}$ heptanesulphonate, and $19.5 \mathrm{~mL}$ of methanol with $\mathrm{pH}$ adjusted to 3.4 with phosphoric acid. The mobile phase was filtered through a $0.2-\mu \mathrm{m}$ cellulose membrane (Whatman, Maidstone, England).

\section{Solution stability studies}

LDME solutions ( $100 \mu \mathrm{g} / \mathrm{mL})$ were prepared in various buffer solutions at $\mathrm{pH}$ 1.72, 3.20, 4.10, 4.96, 5.81 and 6.72. Each LDME solution was stored in water bath set at $37^{\circ} \mathrm{C}$. Samples $(100 \mu \mathrm{L}$ each $)$ were periodically taken from each solution and mixed with IS $(20 \mu \mathrm{g} / \mathrm{mL}$ in $\mathrm{pH} 1.2$ buffer) $100 \mu \mathrm{L}$ and $0.1 \mathrm{~N}$ phosphoric acid $800 \mu \mathrm{L}$. LDME and L-dopa concentrations in the samples were determined by assaying $50 \mu \mathrm{L}$ of the resultant mixture by the HPLC method summarized above.

\section{Dissection of mucosa specimens}

Male New Zealand White rabbits were sacrificed by injecting air into the marginal ear vein. Nasal mucosa was collected by making an incision from the tip of the nose all the way up with a surgical scissor and 
cutting the cartilage along the length of the lateral wall of the nose on each side of the nasal septum from the bottom with a heavy-duty scissor. This was followed by cutting the nasal septum across the top and the bottom with the surgical scissor and pulling off the nasal bone anteriorly to fully expose the nasal cavity. The nasal cartilage plate, which is covered with nasal membrane, was carefully removed by making three cuts on the top, bottom, and along side. Nasal membranes were separated from the underlying cartilage by carefully pushing off the cartilage, with a gloved thumb fingertip, from the lower end.

\section{Preparation of mucosal and serosal extracts}

Mucosal and serosal extraction was carried out in Valia-Chien permeation cells. Freshly excised nasal mucosae were mounted on the cell opening between the two half-cells, with the mucosal epithelium facing the donor half-cell. Both the donor and receptor half-cells were filled with $3.5 \mathrm{~mL}$ of isotonic phosphate buffer at $\mathrm{pH} 7.4$, and mucosal and serosal extracts were collected separately by exposing the mucosal and serosal surfaces of each mucosa, respectively, to the isotonic phosphate buffer at $37^{\circ} \mathrm{C}$ for $8 \mathrm{hr}$. The extraction procedure was repeated three times. The mucosal and serosal extracts, three each, were combined individually and stored in a refrigerator.

\section{LDME degradation study in mucosal and serosal extracts}

The degradation study was conducted by adding $100 \mu \mathrm{L}$ of two LDME solutions (50 and $200 \mu \mathrm{g} / \mathrm{mL}$ ) into $900 \mu \mathrm{L}$ of each extract and incubating them in a shaker bath at $37^{\circ} \mathrm{C}$ for up to $180 \mathrm{~min}$. As a control, $200 \mu \mathrm{g} / \mathrm{mL}$ LDME solution in $1: 1$ mixture of $\mathrm{pH}$ 6.8 and $\mathrm{pH} 7.4$ isotonic phosphate buffer was used. At predetermined time intervals, $100 \mu \mathrm{L}$ was withdrawn from the incubation solution and mixed with $100 \mu \mathrm{L}$ IS solution $(20 \mu \mathrm{g} / \mathrm{mL}$ in $\mathrm{pH} 1.2$ buffer $)$. Fifty microliters of the mixed solution was analyzed by HPLC.

\section{Formulation of nasal delivery systems}

Five nasal compositions were formulated as shown in Table 1. For powder formulations, LDME was mixed with additives and stored in darkness until use. A solution formulation $\mathrm{E}$ was used as a control.
Table 1

LDME formulations for nasal delivery

\begin{tabular}{lrrrrr}
\hline Ingredients & \multicolumn{5}{c}{ Formulations } \\
\cline { 2 - 6 } & \multicolumn{1}{c}{ A } & \multicolumn{1}{c}{ B } & \multicolumn{1}{c}{ C } & \multicolumn{1}{c}{ D } & E \\
\hline LDME (mg) & 600 & 600 & 600 & 600 & 30 \\
N-acetyl-L-cysteine (mg) & 50 & 50 & 50 & 50 & 2.5 \\
2-HPßCD (mg) & 230 & 230 & 230 & 250 & 15 \\
SMCC (mg) & 100 & 100 & 100 & 100 & - \\
Carbopol 974 P (mg) & 20 & - & - & - & - \\
HPC (mg) & - & 20 & - & - & - \\
CMC-Na (mg) & - & - & 20 & - & - \\
Water & - & - & - & - & Qs \\
Total (mg) & 1000 & 1000 & 1000 & 1000 & $1 \mathrm{~mL}$ \\
\hline
\end{tabular}

LDME: levodopa methyl ester, 2-HPßCD: 2-hydroxypropyl- $\beta$ cyclodextrin, SMCC: silicated microcrystalline cellulose, HPC: hydroxypropyl cellulose, $\mathrm{CMC}-\mathrm{Na}$ : carboxymethyl cellulose- $\mathrm{Na}$

\section{Permeation studies}

Franz Diffusion cells were used for LDME permeation study through rabbit nasal mucosae. Formulated powder (Formulation A $\sim \mathrm{D}$ ) and solution (Formulation E) for nasal delivery from Table 1 were loaded to the donor compartment at a dose of $3 \mathrm{mg}$ of LDME; the serosal side was in contact with the receptor compartment. Receptor compartment cells were filled with pH 7.4 phosphate buffer, and the media were stirred by a Teflon-coated magnetic bar to keep them well mixed. The permeation media were maintained at 37 ${ }^{\circ} \mathrm{C}$. The surface area of the receiver cell opening was $1.766 \mathrm{~cm}^{2}$, and the cell volume was $5 \mathrm{~mL}$. At predetermined time intervals, $100 \mu \mathrm{L}$ was withdrawn from the receiver cells and diluted with $900 \mu \mathrm{L}$ of $0.1 \mathrm{~N}$ phosphate solution. The diluted solution $100 \mu \mathrm{L}$ was mixed with $200 \mu \mathrm{L}$ IS solution. Fifty microliters of the mixed solution was analyzed by HPLC.

\section{RESULTS AND DISCUSSION}

The physicochemical stability of LDME was evaluated according to solution $\mathrm{pH}$. As $\mathrm{pH}$ increased, LDME was rapidly hydrolyzed, only $58 \%$ of LDME remaining $5 \mathrm{hr}$ after storage at pH 6.7 as shown in Table 2. The degradation profile of LDME followed first-order kinetics. The elimination rate constants were 0.001 , $0.002,0.002,0.006,0.029$, and 0.106 at $\mathrm{pH} 1.72,3.20$, $4.10,4.96,5.81$, and 6.72, respectively. As shown in Fig. 1, the effect of $\mathrm{pH}$ on the solution stability of LDME in the $\mathrm{pH}$ range above 4.1 was much greater than that in the range below $\mathrm{pH} 4.1$. The log $\mathrm{k}-\mathrm{pH}$ profile showed a linear slope value in $\mathrm{pH}$ ranges above $4.1\left(r^{2}=0.9955\right)$. The total percentages of remaining LDME and forming L-dopa were far less than $100 \%$ at 
Table 2

Remaining (\%) levodopa methyl ester and formed (\%) levodopa in various buffered aqueous solutions

\begin{tabular}{|c|c|c|c|c|c|c|c|c|c|c|c|c|}
\hline \multirow{2}{*}{$\begin{array}{l}\text { Time } \\
\text { (hr) }\end{array}$} & \multicolumn{2}{|c|}{ pH 1.72} & \multicolumn{2}{|c|}{$\mathrm{pH} 3.20$} & \multicolumn{2}{|c|}{$\mathrm{pH} 4.10$} & \multicolumn{2}{|c|}{$\mathrm{pH} 4.96$} & \multicolumn{2}{|c|}{ pH 5.81} & \multicolumn{2}{|c|}{ pH 6.72} \\
\hline & LDME & L-dopa & LDME & L-dopa & LDME & L-dopa & LDME & L-dopa & LDME & L-dopa & LDME & L-dopa \\
\hline 0 & 100 & 0 & 100 & 0 & 100 & 0 & 100 & 0 & 100 & 0 & 100 & 0 \\
\hline 1 & $99.4 \pm 1.2$ & $3 \pm 0$ & $2.7 \pm 3.1$ & $5 \pm 0$ & $98.9 \pm 1.9$ & $5 \pm$ & $98.1 \pm 1.0$ & $1.0 \pm 0$ & $97.6 \pm 1.2$ & $0.9 \pm$ & $92.4 \pm 1.9$ & $6.9 \pm 0.09$ \\
\hline 3 & $101.8 \pm 2.3$ & $0.8 \pm 0.03$ & $101.8 \pm 2.1$ & $0.8 \pm 0.01$ & $97.2 \pm 1.5$ & $1.0 \pm 0.07$ & $100.4 \pm 2.9$ & $1.2 \pm 0.04$ & $98.9 \pm 2.9$ & $1.4 \pm 0.08$ & $73.2 \pm 2.9$ & $15.5 \pm 0.08$ \\
\hline 5 & $98.0 \pm 3.2$ & $0.8 \pm 0.1$ & $102.3 \pm 1.5$ & $0.9 \pm 0.1$ & $103.1 \pm 2.7$ & $1.0 \pm 0.02$ & $99.4 \pm 1.8$ & $1.5 \pm 0.04$ & $92.9 \pm 1.4$ & $2.1 \pm 0.09$ & $58.4 \pm 1.9$ & $23.1 \pm 1.0$ \\
\hline 21 & $97.9 \pm 1.3$ & $1.5 \pm 0.2$ & $97.7 \pm 1.0$ & $1.9 \pm 0.07$ & $96.1 \pm 2.5$ & $3.2 \pm 0.08$ & $87.7 \pm 0.9$ & $8.9 \pm 0.08$ & $55.1 \pm 1.1$ & $24.2 \pm 0.9$ & $11.0 \pm 0.8$ & $43.1 \pm 1.1$ \\
\hline
\end{tabular}

Data are expressed as the mean \pm S.D. $(n=3)$. LDME: levodopa methyl ester. L-dopa: levodopa. 


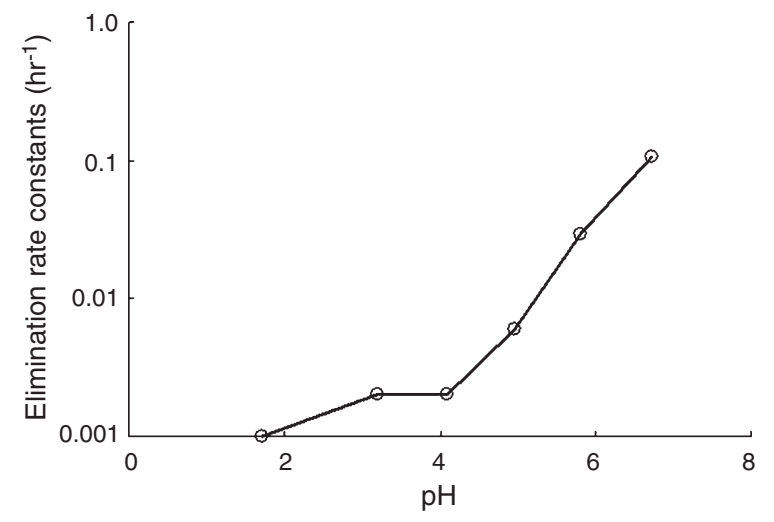

Fig. 1. Elimination rate constants of LDME in buffer solutions with various $\mathrm{pH}$. LDME: levodopa methyl ester.

pH 6.72. This was thought to be due to the involvement of other degradative reactions in LDME metabolism, in addition to hydrolysis.

To determine the amount of LDME enzymatically degraded before and after permeation, mucosal and serosal extracts were employed. Degradation profiles were investigated by monitoring the disappearance of LDME and the appearance of its main metabolite, Ldopa, using two concentrations ( 50 and $200 \mu \mathrm{g} / \mathrm{mL}$ ) of LDME. The disappearance of LDME in the mucosal and serosal extracts followed first-order kinetics as shown in Fig. 2 (A). LDME was very rapidly degraded in nasal mucosa extracts; more than $90 \%$ of LDME was degraded at $30 \mathrm{~min}$ while more than $90 \%$ of LDME remained in the isotonic buffer (control) which was used for extracting enzymes from nasal mucosae. There were no significant differences in degradation

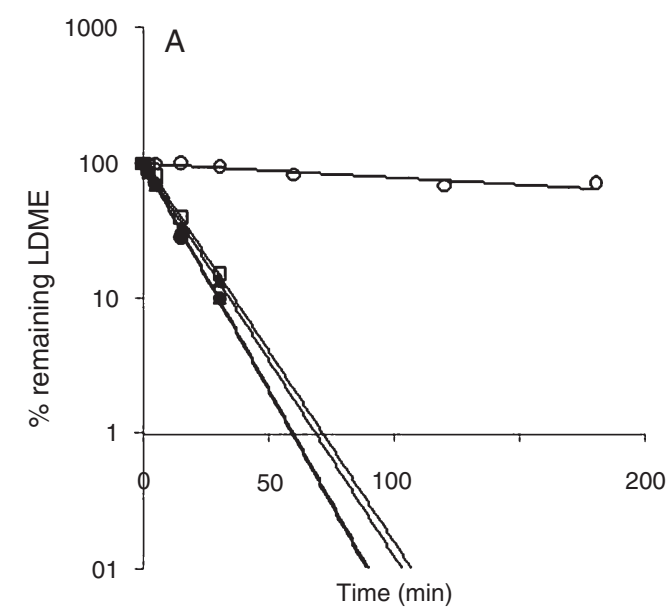

rates between the extracts from the mucosal and serosal surfaces. Elimination rate constants were calculated to be 0.08 and $0.07 \mathrm{~min}^{-1}$ in the mucosal and serosal extracts, respectively. In addition, degradation rates were not significantly different between low and high concentrations of LDME, of which the half-life was 8.9 and $8.8 \mathrm{~min}$, respectively. This was a much more rapid degradation, compared to levodopa butyl ester (degradation half-life of $144 \mathrm{~min}$ ) in a study by Kao et al. (2000) [13], although they used nasal perfusates.

As shown in Fig. 2 (B), more than 80\% L-dopa was formed at $30 \mathrm{~min}$ regardless of which extract and drug concentration were used. On the contrary, LDME was less degraded in isotonic buffer-therefore, L-dopa was not formed much. Based on the results, it was speculated that LDME could be a favorable prodrug of L-dopa, due to its rapid degradation and appearance of L-dopa in nasal mucosa extracts.

Since LDME as a solution formulation was very unstable, a powder formulation was obtained to ensure stability. The addition of Carbopol, HPC, and CMC$\mathrm{Na}$ at a concentration of $2 \%$ in Formulation $\mathrm{A}, \mathrm{B}$, and $\mathrm{C}$ (Table 1), respectively, allowed adhesiveness of the powder formulations $[14,15]$. SMCC was added to the adhesives to enhance absorption-according to a study, the addition of MCC to HPC enhanced nasal absorption of drugs such as leuprolide, calcitonin, and FITC-dextran. In the study, MCC was considered to function as an absorption enhancer by causing a locally high concentration of drugs near the nasal mucosa surface, while HPC was thought to increase retention of drugs on the nasal mucosa, due to its gel-forming property [14].

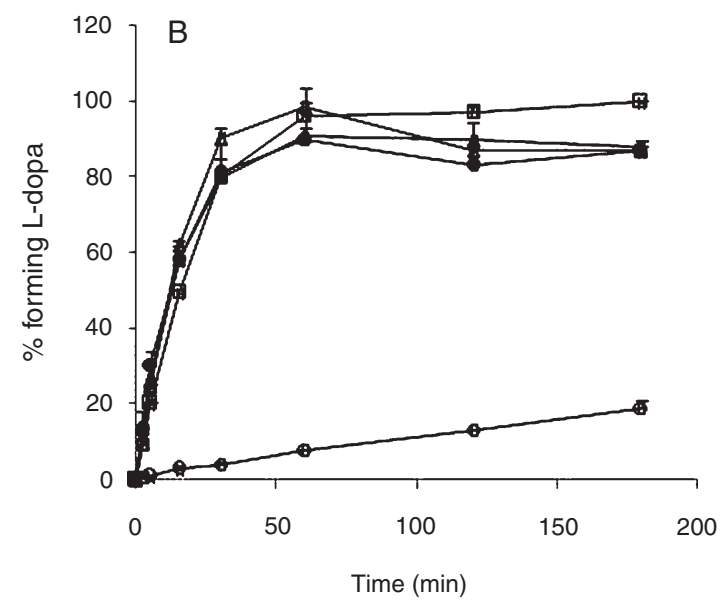

Fig. 2. Profiles of LDME degradation (A) and L-dopa formation (B) in nasal mucosa extracts (mean \pm S.D., $n=3$ ). LDME: levodopa methyl ester, L-dopa: levodopa. $\circ$ : control, $\bullet$ : low concentration in mucosal extract, $\triangle$ : high concentration in mucosal extract, $\Delta:$ low concentration in serosal extract, $\square$ : high concentration in serosal extract. 


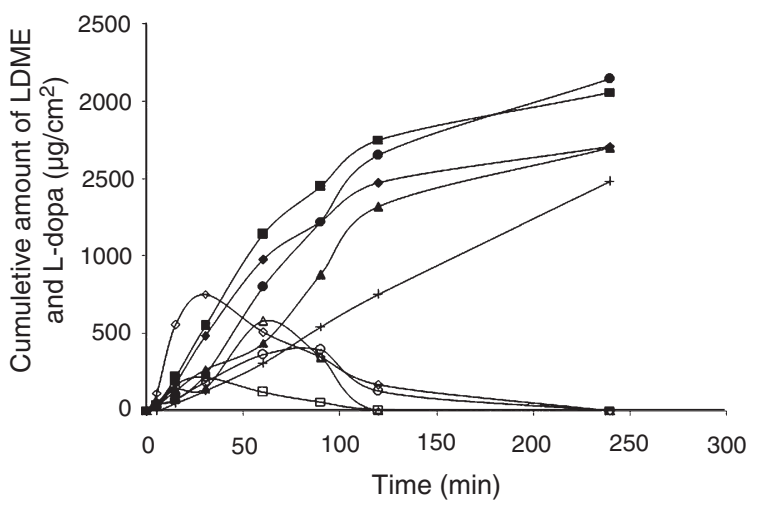

Fig. 3. Appearance profiles of LDME and L-dopa in the receptor cells through nasal mucosa following various formulations (mean \pm S.D., $n=3$ ). LDME: levodopa methyl ester, L-dopa: levodopa, FN: formulation. $\circ$ : LDME from FN-A, •: L-dopa from FN-A, $\triangle$ : LDME from FN-B, $\boldsymbol{\Delta}$ : L-dopa from FN-B, $\square$ : LDME from FN-C, $\mathbf{\square}:$ L-dopa from FN-C, $\diamond:$ LDME from FN-D, $\diamond:$ L-dopa from $\mathrm{FN}-\mathrm{D}$, +: L-dopa from $\mathrm{FN}-\mathrm{E}$.

Table 3

Appearance rates of levodopa in the receptor cell

\begin{tabular}{lcc}
\hline FN & Flux $\left(\mu \mathrm{g} / \mathrm{cm}^{2} / \mathrm{hr}\right)$ & Lag time $(\mathrm{hr})$ \\
\hline A & $1.07 \pm 0.39$ & $0.26 \pm 0.10$ \\
$\mathrm{~B}$ & $0.68 \pm 0.15$ & $0.09 \pm 0.06$ \\
$\mathrm{C}$ & $0.90 \pm 0.46$ & $0.09 \pm 0.07$ \\
$\mathrm{D}$ & $1.05 \pm 0.32$ & $0.08 \pm 0.05$ \\
$\mathrm{E}$ & $0.35 \pm 0.08$ & $0.14 \pm 0.04$ \\
\hline \multicolumn{2}{l}{ Data are expressed as the mean \pm S.D. $(n=3) . \mathrm{FN}$ : formulation. }
\end{tabular}

$\mathrm{N}$-acetyl-L-cysteine, a mucolytic agent, was employed to reduce nasal fluid viscosity and improve accessibility of the drug to the epithelial membrane [16]. 2-HPßCD (23\%) was used for improving nasal drug absorption either by increasing aqueous drug solubility or by enhancing nasal drug permeability [17]. In addition, it is known to reduce nasal toxicity [18]. Due to its lack of mucosal adhesive agents, Formulation D was used as a control for Formulation A, B, and C. As a control for powder formulations, solution formulation $\mathrm{E}$ was constructed.

The permeation study was conducted using powder formulations. As shown in Fig. 3, LDME concentrations increased in the receptor cell for the first several min and then declined. Table 3 shows the appearance rates of L-dopa in the receptor compartment. LDME from solution formulation was not detected in the receptor cell. This was possibly because LDME was rapidly hydrolyzed to L-dopa in donor cells before permeation.

The appearance rates of L-dopa from powder formulations were higher than those from solution per- meation. Among adhesive agents, Carbopol revealed the highest permeation enhancing effects, while HPC showed the lowest. Lag times were very short, ranging between $5 \sim 15 \mathrm{~min}$. The appearance rate of L-dopa was not affected by the presence of adhesive agents (Formulation A, C and D).

Further in vivo pharmacokinetic study is required to confirm these in vitro results because the in vitro study is not able to provide the information on the distribution and elimination of a drug. In addition, considering that nasal irritation was reported to be a limiting factor of apomorphine nasal delivery systems [19], investigation of the nasal irritation with the formulated nasal systems is needed. Despite the limitations, the results of this study can be valuable as a preliminary data for formulating the LDME nasal delivery systems.

\section{CONCLUSIONS}

These results suggested that LDME nasal powder formulations would be useful delivery systems of Ldopa, owing to its high appearance rates and stability, compared to solution formulations.

\section{DECLARATION}

\section{CONFLICT OF INTEREST}

The authors declare that they have no conflicts of interest to disclose.

\section{ACKNOWLEDGMENTS}

This work was supported by the Korea Science and Engineering Foundation (KOSEF) grant funded by the Korea government (MOST).

\section{REFERENCES}

[1] Cotzias CG, Van Woert MH, \& Schiffer LM (1967) Aromatic amino acids and modification of parkinsonism. New Engl J Med, 276, 374-379.

[2] Okereke CS (2002) Role of integrative pharmacokinetic and pharmacokydnamic optimization strategy in the management of Parkinson's disease patients experiencing motor fluctuations with levodopa. J Pharm Pharma Sci, 5, 146-161.

[3] Chen JJ, Nelson MV, \& Swope DM (2008) Parkinson's disease. In Pharmacotherapy: A Pathophysiologic Approach, Dipiro JT, Talbert RL, Yee GC, Matzke GR, Wells BG, Posey ML, eds. McGraw Hill, New York, pp. 977-988.

[4] Simon N, Gantcheva R, Bruguerolle B, \& Viallet F (2004) The effects of a normal protein diet on Levodopa plasma kinetics 
in advanced Parkinson's disease. Parkinsonism Relat Disord, 10, 137-142.

[5] Müller T, Erdmann C, Bremen D, Schmidt WE, Muhlack S, Woitalla D, \& Goetze O (2006) Impact of gastric emptying on levodopa pharmacokinetics in Parkinson disease patients. Clin Neuropharmacol, 29, 61-67.

[6] Johnston BT, Li Q, Castell JA, \& Catell DO (1995) Swallowing and esophageal function in Parkinson's disease. Am J Gastroenterol, 90, 1741-1746.

[7] Nyholm D (2006) Pharmacokinetic optimization in the treatment of Parkinson's disease: an update. Clin Pharmacokinet, 45, 109-136

[8] Illum L (2000) Transport of drugs from the nasal cavity to the central nervous system. Eur J Pharm Sci, 11, 1-18.

[9] Dahlin M, Jansson B, \& Björk E (2001) Levels of dopamine in blood and brain following nasal administration to rats. Eur J Pharm Sci, 14, 75-80.

[10] Costantino HR, Illum L, Brandt G, Johnson PH, \& Quay SC (2007) Intranasal delivery: physicochemical and therapeutic aspects. Int J Pharm, 337, 1-24.

[11] Kim TK, Kang W, Chun IK, Oh SY, Lee YH, \& Gwak HS (2009) Pharmacokinetic evaluation and modeling of formulated levodopa nasal delivery systems. Eur J Pharm Sci, 38, 525-532.

[12] Zangaglia R, Stocchi F, Sciarretta M, Antonini A, Mancini F, Guidi M, Martignoni E, \& Pacchetti C (2010) Clinical experiences with levodopa methylester (Melevodopa) in patients with Parkinson disease experiencing motor fluctuations: an open-label observational study. Clin Neuropharmacol, 33, 61-66.

[13] Kao HD, Traboulsi A, Itoh S, Dittert L, \& Hussain A (2000) Enhancement of the systemic and CNS specific delivery of Ldopa by the nasal administration of its water soluble prodrugs. Pharm Res, 17, 978-984.

[14] Suzuki Y \& Makino Y (1999) Mucosal drug delivery using cellulose derivatives as a functional polymer. J Contr Rel, 62, 101-107.

[15] Bonacucina G, Cespi M, Misici-Falzi M, \& Palmieri GF (2005) Rheological, adhesive and release characterization of semisolid carbopol/tetraglycol systems. Int J Pharm, 307, 129-140.

[16] Matsuyama T, Morita T, Horikiri Y, Yamahara T, \& Yoshino $H$ (2006) Improved nasal absorption of salmon calcitonin by powdery formulation with $\mathrm{N}$-acetyl-L-cysteine as a mucolytic agent. J Contr Rel, 115, 183-188.

[17] Challa R, Ahuja A, Ali J, \& Khar RK (2005) Cyclodextrins in drug delivery: an updated review. AAPS PharmSciTech, 14, E329-E357.

[18] Zhang Y, Jiang XG, \& Yao J (2001) Nasal absorption enhancement of insulin by sodium deoxycholate in combination with cyclodextrins. Acta Pharmacol Sin, 22, 1051-1056.

[19] Dewey RB Jr, Maraganore DM, Ahlskog JE, \& Matsumoto JY (1998) A double-blind, placebo controlled study of intranasal apomorphine spray as a rescue agent for off-states in Parkinson's disease. Mov Disord, 13, 782-787. 